\title{
PGPRs and nitrogen-fixing legumes: a perfect team for efficient Cd phytoremediation?
}

\author{
María T. Gómez-Sagasti ${ }^{1}$ and Daniel Marino ${ }^{1,2}$ \\ ${ }^{1}$ Laboratory of Plant Physiology, Department of Plant Biology and Ecology, University of the Basque Country, Bilbao, Spain \\ 2 Ikerbasque, Basque Foundation for Science, Bilbao, Spain
}

Edited by:

David W. M. Leung, University of

Canterbury, New Zealand

\section{Reviewed by:}

Peter Gresshoff, The University of Queensland, Australia

Manoj K. Sharma, Jawaharlal Nehru

University, India

Sandra Citterio, University of

Milano-Bicocca, Italy

\section{${ }^{*}$ Correspondence:}

María T. Gómez-Sagasti, Laboratory of Plant Physiology, Department of Plant Biology and Ecology, University of the Basque Country, P.O. Box 644,

E-48080 Bilbao, Spain

e-mail: mariateresa.gomez@ehu.es
Cadmium $(\mathrm{Cd})$ is a toxic, biologically non-essential and highly mobile metal that has become an increasingly important environmental hazard to both wildlife and humans. In contrast to conventional remediation technologies, phytoremediation based on legumerhizobia symbiosis has emerged as an inexpensive decontamination alternative which also revitalize contaminated soils due to the role of legumes in nitrogen cycling. In recent years, there is a growing interest in understanding symbiotic legume-rhizobia relationship and its interactions with $\mathrm{Cd}$. The aim of the present review is to provide a comprehensive picture of the main effects of $\mathrm{Cd}$ in $\mathrm{N}_{2}$-fixing leguminous plants and the benefits of exploiting this symbiosis together with plant growth promoting rhizobacteria to boost an efficient reclamation of $\mathrm{Cd}$-contaminated soils.

Keywords: cadmium, PGPRs, legume, nitrogen fixation, symbiosis, phytoremediation
LEGUMES, A PROMISING TOOL FOR CD PHYTOREMEDIATION An increasingly industrialized global economy over the last century has led to a dramatic increase in production and release of hazardous metals to the environment (Gerhardt et al., 2009). Among all the non-essential metals, cadmium (Cd) has received great attention in soil science and plant nutrition mainly due to (1) its phytotoxic impact ranging from growth reduction, wilting, and chlorosis to cell death (Gallego et al., 2012); (2) its relative high mobility in the soil-plant system, which implies Cd dissemination throughout the food chain, even becoming a serious threat to ecosystem and human health (Burger, 2008) and; (3) its long halflife in soil system varying between 100 and 1,000 years (Central Pollution Control Board [CPCB], 2007). The resulting detrimental effects derived from excess of $\mathrm{Cd}$ on environment and human health are well documented (Clemens et al., 2013).

Today, environmental managers are increasingly becoming aware of the importance to remediate Cd-contaminated areas using biological systems (microorganisms and/or plants), which are more ecologically sound, less labor-intensive, safe, and economically advantageous than conventional methods based on physico-chemical processes (e.g., land filling, chemical fixation, and leaching). Concerning bioremediation, plant-assisted remediation or phytoremediation has been highlighted for its potential for in situ removal of Cd from soils (Salt et al., 1995). Phytoremediation of Cd-contaminated soils encompasses three different strategies: (1) phytoextraction (uptake and accumulation of metal from soils into the plant's harvestable parts); (2) phytostabilization (complexation of metal in the rhizosediment decreasing its solubility/bioavailability) and; (3) rhizofiltration (absorption of metal by roots).

Although phytoremediation is a promising technology, its feasibility depends on site conditions, soil properties, and plants sensitivity to the toxic metal. In particular, the poor soil structure, low water-holding capacity, lack of organic matter (OM) and its associated nutrients such as nitrogen $(\mathrm{N})$ and phosphorous $(\mathrm{P})$ are some of the distinctive features of metal-polluted soils that are a matter of importance in the early stages of phyremediation (i.e., in the establishment of plant cover; Wong, 2003). In this regard, the exploitation of symbiotic relationship between leguminous plants and rhizobia is presented as an attractive and cost-effective alternative to improve the nitrogen input into the plant-soil system compared with the use of expensive synthetic $\mathrm{N}$-fertilizers (United States Department of Agriculture, Economic Research Service [USDA-ERS], 2013). Moreover, the contribution of soil bacteria, other than rhizobia, to improve the metal remediation capacity of symbiotic legumes represents a growing area of research. These bacteria are known as plant growthpromoting rhizobacteria (PGPRs). This review summarizes some of the recent advances in this field and highlights the potential of this three partner relationship legume-rhizobia-PGPRs for $\mathrm{Cd}$ detoxification.

Legumes (Fabaceae or Leguminosae) is the third largest angiosperm family, with more than 700 genera and 18,000 species with an exceptionally wide range of habitats (Lewis et al., 2005). One of the outstanding characteristics of this family is that most legumes have the ability to establish a symbiotic relationship with soil nitrogen-fixing $\left(\mathrm{N}_{2}\right.$-fixing) rhizobacteria, known collectively as rhizobia, e.g., Rhizobium, Mesorhizobium, Bradyrhizobium, Azorhizobium, Allorhizobium, or Sinorhizobium (Velázquez et al., 2010).

The symbiotic process is initiated with the production of Nod Factors (NFs) by rhizobia in response to plant root exudates containing (iso)flavonoids. The perception of NFs by the plant will then launch the bacterial infection (Oldroyd, 2013). This 
molecular dialog culminates in the formation of a new organ, the nodules, which are formed in the roots and in rare cases in the stems. Inside the nodules, the symbiotic nitrogen fixation (SNF) process takes places. Plants provide a carbon source to the bacteria to fuel the energy demand of the SNF and also a microaerophilic environment inside the nodules, which is compatible with nitrogenase (Nase) complex functioning. The enzyme Nase reduces the atmospheric dinitrogen to ammonia, which will be incorporated into organic forms and then exported from the nodules to sustain plant growth (Oldroyd, 2013).

Thus, SNF also makes legumes ideal pioneers to colonize and restore the quality and health of $\mathrm{N}$-limited environments, a common feature of metal-contaminated soils (Zaidi et al., 2012). This capacity together with legumes deep-reaching root system and high biomass are ideal traits for efficient phytoremediation of $\mathrm{Cd}$.

\section{LEGUME-RHIZOBIA SYMBIOSIS IS SENSITIVE TO CD}

Cadmium is a very toxic element even at low concentrations, being ranked number 7 by the Agency for Toxic Substances and Disease Registry (ATSDR, 2013). The exposure to Cd can affect considerably the symbiosis establishment, nodule formation and SNF. Cd inhibitory effects on nodulation and SNF depend on the Cd concentration, its bioavailability in the plant growth conditions (agar plates, hydroponics, soil, etc.), the length of the exposure (gradual exposure to low concentrations or a severe shock), and the specific sensibility of species. Main Cd effects on legume nodules are summarized in Table $\mathbf{1 .}$

The harmful outcome of Cd on nitrogen fixation is in part due to a direct effect of $\mathrm{Cd}$ in the survival of free-living rhizobia in the soil (Smith, 1997; Giller et al., 1998), which results even in their gradual extinction (Broos et al., 2005). For instance, effective Rhizobium leguminosarum bv. trifolii population did not survive after long-term incubation of soils containing $7.1 \mathrm{mg} \mathrm{Cd} \mathrm{kg}-1$ (Chaudri et al., 1992) and soils amended with metal-enriched liquid sludge and metal salts began to show impacts on rhizobia over time (11 year time-lapse; Chaudri et al., 2008).

Besides the potential deleterious effects of $\mathrm{Cd}$ on the growth and survival of rhizobia, nodulation, and the morphology of the nodules are also considerably affected. For instance, the addition of 16 and $20 \mathrm{mg} \mathrm{Cd} \mathrm{kg}^{-1}$ soil caused great inhibition of root growth and nodulation in soybean (Glycine max; Chen et al., 2003; Sheirdil et al., 2012). Manier et al. (2009) conducted a specialized "rhizotron" experiment exposing white clover (Trifolium repens) to fourteen topsoils from a strongly metal-contaminated $(\mathrm{Cd}, \mathrm{Zn}$, and $\mathrm{Pb}$ ) area and observed a significant decrease in nodulation index (i.e., the number of nodules per gram of the total fresh biomass) at about $2.64 \mathrm{mg} \mathrm{Cd} \mathrm{kg}^{-1}$ in these soils. The structure of the nodule was also negatively influenced by $\mathrm{Cd}$ exposure in white lupin (Lupinus albus), resulting in an occluded intracellular spaces of nodule cortex, alterations in symbiosomes, enrichment

Table 1 | Summary of the main deleterious cadmium effects reported in legume nodules.

\begin{tabular}{ll}
\hline Cadmium effects* Legume \\
\hline
\end{tabular}

Nodule formation and functioning

Nodule number/weight

Arachis hypogaea (Bianucci et al., 2013); Cajanus cajan (Garg and Aggarwal, 2011); Glycine max (Chen et al., 2003); Lupinus albus (Carpena et al., 2003); Medicago sativa (Neumann et al., 1998); Pisum sativum (Hernández etal., 1995); Vigna radiata (Muneer et al., 2012)

Nodule ultrastructure alteration A. hypogaea (Bianucci etal., 2013); G. max (Chen etal., 2003); L. albus (Carpena et al., 2003); M. sativa (Shvaleva et al., 2010)

Symbiotic nitrogen fixation (SNF) inhibition C. cajan (Garg and Aggarwal, 2011); G. max (Balestrasse et al., 2004); L. albus (Sánchez-Pardo et al., 2013); M. sativa (Shvaleva et al., 2010); Medicago truncatula (Marino et al., 2013); P. sativum (Hernández etal., 1995)

\section{Oxygen control}

Reactive oxygen species (ROS)

over-production

Oxidative damage A. hypogaea (Bianucci et al., 2013); C. cajan (Garg and Bhandari, 2012)

A. hypogaea (Bianucci et al., 2013); C. cajan (Garg and Aggarwal, 2011); G. max (Balestrasse et al., 2004); L. albus (Sánchez-Pardo etal., 2013); Phaseolus vulgaris (Loscos et al., 2008)

Antioxidant system deregulation C. cajan (Garg and Aggarwal, 2011); G. max (Balestrasse et al., 2004); L. albus (Carpena et al., 2003); M. sativa (Shvaleva et al., 2010); M. truncatula (Marino et al., 2013); P. vulgaris (Loscos et al., 2008); V. radiata (Muneer etal., 2012)

Leghemoglobin (Lb) degradation C. cajan (Garg and Aggarwal, 2011); G. max (Balestrasse et al., 2004); L. albus (Carpena et al., 2003); M. truncatula (Marino etal., 2013); P. vulgaris (Loscos et al., 2008); V. radiata (Muneer et al., 2012)

\section{Primary metabolism}

Nitrogen assimilation G. max (Balestrasse et al., 2006); L. albus (Sánchez-Pardo et al., 2013)

Carbon metabolism/balance alteration

\footnotetext{
*These effects are dependent on Cd concentration, exposure time, plant species, and growth conditions.
} 
in Cd of cell walls and, finally, reduction of effective $\mathrm{N}_{2}$-fixing area (Carpena et al., 2003).

One of the most known effects related to Cd toxicity in legumes nodules is the overproduction of reactive oxygen species (ROS). In general, the mechanism underlying ROS generation upon $\mathrm{Cd}$ exposure remains to be elucidated. Although Cd itself is not redox active since it is not able to trigger the Fenton-type reactions (Salin, 1988), Cd-related ROS production can be indirectly linked to impairment of the antioxidant machinery (Sandalio et al., 2001), to disruption of the electron transport chain, and somehow to the activation of NADPH oxidases in membranes (Romero-Puertas et al., 2004; Cuypers et al., 2010).

Symbiotic nitrogen fixation inhibition related to ROS overproduction in legume nodules has been shown to be related to three different motives; (1) a direct inactivation of Nase, which is extremely sensitive to oxygen and to oxidation by ROS (Naya et al., 2007); (2) leghemoglobin (Lb) degradation, a protein in charge of binding free $\mathrm{O}_{2}$ in the infected cells cytosol to supply to the bacteroids for their respiration (Mathieu et al., 1998; Marino etal., 2006); and (3) sucrose synthase downregulation, a key enzyme in nodule carbon metabolism that hydrolyses the sucrose coming from the photosynthetic process to load the bacteroids with carbon skeletons for energy obtaining (Marino et al., 2009).

When legumes have been exposed to high Cd concentrations or long exposure, the high mobility of Cd brought its translocation to shoots and provoked photosynthesis impairment, leaves chlorosis, and oxidative damage in nodules. So, it seems that the nitrogen fixation inhibition related to a severe Cd exposure observed in different legumes like soybean (Balestrasse et al., 2006), white lupin (Carpena etal., 2003), or mung bean (Vigna radiata; Muneer et al., 2012) would be associated to a general plant breakdown rather than to a specific effect of Cd in nodules affecting SNF. However, in a recent work with nodulated Medicago truncatula plants grown in split-root system, the differential application of $\mathrm{Cd}$ to one part of the root led to a specific activation of nodule antioxidant machinery and a concomitant inhibition of SNF (Marino et al., 2013). In that work, SNF inhibition was related to Lb and Nase down-regulation, whilst sucrose synthase did not vary compared to controls (Marino et al., 2013). This is in agreement with other works showing that $\mathrm{Cd}$ application provoked a rapid decrease in Lb content, for instance in soybean (Balestrasse et al., 2004) and common bean (Phaseolus vulgaris; Loscos et al., 2008). Interestingly, the heterologous overexpression of a flavodoxin from the filamentous cyanobacterium Anabaena variabilis in Sinorhizobium meliloti partially prevented Cd toxicity effects on Nase activity in alfalfa (Medicago sativa; Shvaleva et al., 2010). Flavodoxins are prokaryotic electron carrier proteins and have been suggested to play a positive role in ROS detoxification (Redondo et al., 2009). In general, among the different regulation pathways that control SNF under abiotic stresses, initial Cd effects on Medicago sp. nodules nitrogen fixing capacity seem to be related to Nase down-regulation. This inhibition could be a consequence of the effect reported on $\mathrm{Lb}$, resulting in intracellular free- $\mathrm{O}_{2}$ increase that could damage Nase. In contrast, although in other legume species the effect of ROS-producing abiotic stresses has been related to carbon limitation, this does not seem to be the principal inductor of SNF inhibition in Medicago sp. (Larrainzar et al., 2014).

Since legumes are sensitive to $\mathrm{Cd}$, selecting legume species or genotypes with increased tolerance to $\mathrm{Cd}$ is a must to promote their use in remediation of Cd-contaminated soils (Ahmad et al., 2012a). In this perspective, a number of legumes, especially Anthyllis, Cytisus, Lotus, Lupinus, Genista, Glycine, Ononis, Ornithopus, Pisum, several Trifolium species, Vicia, etc (Pajuelo etal., 2007), have shown encouraging results and they have been proposed as promising tools for reclamation of metalcontaminated areas. As occurs with other plant species, the success of legume-based phytoremediation depends mainly on three factors; (1) the metal disponibility for the plant; (2) the capacity of the legumes to cope with metal toxicity; and (3) the ability of legumes for immobilizing $\mathrm{Cd}$ in roots (ideal for the phytostabilization purposes) and its uptake, translocation and accumulation in shoots (key features for phytoextraction; Sessitsch et al., 2013). Considering these bottlenecks, in recent years, researchers have taken advantage of rhizosphere inhabitants/rhizobacteria associated with legumes to maximize their capacity/effectiveness to phytoremediate Cd-polluted soils (Figure 1A). In this context, PGPRs deserve special attention because of their wide variety of benefits that often enhance plant performance (Mehboob et al., 2013; Figure 1).

\section{THE "HELPER" ROLE OF PGPRS TO LEGUME-RHIZOBIA SYMBIOSIS IN THE LIGHT OF PHYTOREMEDIATION}

Broadly, PGPRs may live inside the plant or in the rhizosphere. PGPRs include free-living $\mathrm{N}_{2}$-fixing bacteria that prompt plant growth viz., Azospirillum, Azotobacter, Acetobacter Bacillus, Burkholderia, Azoarcus, and several species of the family Enterobacteriaceae (Hayat et al., 2010). Plant fitness stimulation by PGPRs is achieved by a set of traits which include: synthesis and providing of growth precursors, enhancement of nutrient acquisition, and their beneficial role as biocontrol agents against phytopathogens (reviewed in Lichtfouse, 2009 and Mehboob et al., 2013). More interestingly, PGPRs can interact synergistically, or function as "helper" bacteria to improve the performance of SNF (Figure 1B). Basically, PGPRs enhance SNF through promoting root development in general and root hair formation in particular, resulting in more potential colonization sites for rhizobia. In this regard, numerous studies stand out the mechanisms of action of PGPRs (Ahemad and Kibret, 2014). Also, SNF improvement has been associated to a direct effect of PGPRs on nodule metabolism, although how this is achieved is not still known.

Related to root development, PGPRs stimulate SNF through four interrelated traits: (1) the systematic induction of secondary metabolites such as flavonoids in root exudates and B-group vitamins and phytohormones like auxins, citokinins, and gibberellins; (2) the control of low levels of ethylene by the 1-aminocyclopropane-1-carboxylic acid (ACC)-deaminase. This enzyme catalyzes the conversion of ACC, the immediate precursor of ethylene synthesis in plants, to ammonia and $\alpha$-ketobutyrate; (3) the solubilisation and uptake of soil nutrients (particularly, N, $\mathrm{P}$, and $\mathrm{K}$ ); and (4) the production and secretion of sideropheres (i.e., low-molecular mass iron chelators that solubilize iron from minerals or organic compounds). 

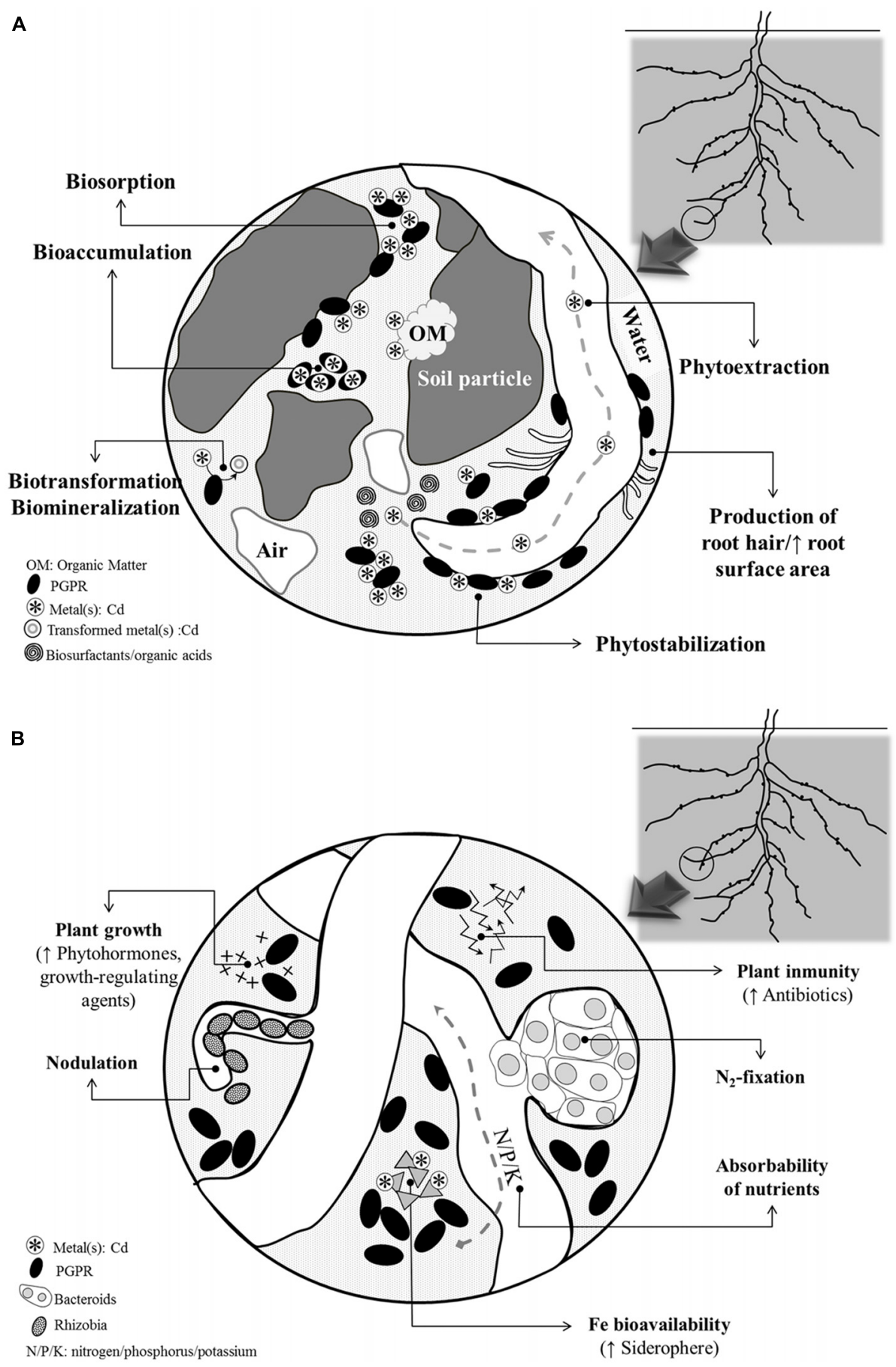

FIGURE 1 | Summary of the main processes that (A) influence metal bio/phytoremediation efficiency during PGPRs-plant interaction and (B) are benefited from the interaction between PGPRs and $\mathrm{N}_{2}$-fixing legumes.

The combined inoculation of Rhizobium tropici CIAT899 and Rhizobium etli ISP42 together with Azospirillum brasilense on common bean, promoted seedlings root branching, and allowed a longer and more persistent exudation of nod-gene-inducing flavonoids that, ultimately, had positive effect on nodule organogenesis (Dardanelli et al., 2008). Moreover, indole acetic acid
(IAA) production and ACC-deaminase activity of Azospirillum played an important role in common bean nodulation response, particularly under low $\mathrm{P}$ conditions in field trial (Remans et al., 2008). In this sense, Cassán etal. (2009) also observed that IAA, gibberellic acid (G3), and zeatin ( $\mathrm{Z}$ ) synthesis was promoted by the cooperative interaction between $A$. brasilense and 
Bradyrhizobium japonicum E109 in soybean. The authors suggested that the over-production of these molecules was behind the enhancement of legumes rhizobial infection, nodule formation, and SNF. Previous work using Bacillus sp. also underlined the ability of these bacteria to enhance IAA, G3, and Z content together with nodule $\mathrm{Lb}$ concentration, Nase activity, and $\mathrm{N}_{2}$-fixation efficiency in common bean (Figueiredo et al., 2008). Additionally, in a field experiment also with common bean, $\mathrm{N}_{2}$-fixing Bacillus subtilis (OSU-142) and P-solubilizing Bacillus megaterium coinoculation with $R$. leguminosarum bv. phaseoli increased $\mathrm{N}$ and $\mathrm{P}$ solubility and, as a result, plants experienced an increase in nodulation and an improvement in growth and yield parameters (Elkoca et al., 2010). Furthermore, some Bacillus sp. prompted nodulation and SNF of pea (Pisum sativum) by phosphate solubilisation (Mishra et al., 2009a) and IAA production (Mishra et al., 2009b) and enhanced nodulation of pigeon pea
(Cajanus cajan) by the production and secretion of sideropheres (Rajendran et al., 2008).

In addition to the above mentioned studies, it has been found that pseudomonads in consortium with Bradyrhizobium japonicum and $R$. phaseoli caused a significant increase of ACC-deaminase activity resulting in decreased levels of ethylene, which in turn was positively correlated with root elongation and enhanced nodulation in mung bean (Shaharoona et al., 2006; Ahmad et al., 2012b) and lentil plants (Lens culinaris; Zahir et al., 2011; Iqbal et al., 2012). Mishra et al. (2011) also demonstrated that the coinoculation of Pseudomonas sp. and R. leguminosarum increased Lb content (46\%) and the total iron (116\%) of $L$. culinaris compared to the inoculation with $R$. leguminosarum alone, presumably due to microbial siderophore utilization. Moreover, the authors showed an increase in total $\mathrm{N}(52 \%)$ and $\mathrm{P}$ (89\%) uptake and suggested that it was the result of root growth

Table 2 | $\mathbf{N}_{2}$-fixing legumes and PGPRs assisted phytoremediation of Cd-contaminated soils.

\begin{tabular}{|c|c|c|c|c|}
\hline Legume & PGPR & Benefits (under Cd threat) & Potential use & Reference \\
\hline \multirow[t]{3}{*}{ Phaseolus vulgaris } & Siderophore-producing bacterial strain & $\uparrow$ Siderophore production & PS & Tripathi etal. (2005)* \\
\hline & KNP9 (probably a strain of & $\uparrow$ Root and shoot growth (height and weight) & & \\
\hline & Pseudomonas putida) & $\uparrow$ Chlorophyll content & & \\
\hline \multirow[t]{3}{*}{ Pisum sativum } & Pseudomonas brassicacearum strain & $\uparrow \mathrm{Cd}$ accumulation in plants & $\mathrm{PX}$ & Engqvist et al. (2006) \\
\hline & Am3 & $\downarrow$ Shoot and seed biomass and P & & \\
\hline & & accumulation & & \\
\hline \multirow[t]{4}{*}{ Pisum sativum } & P. brassicacearum Am3, Pseudomonas & $\uparrow$ Root and shoot biomass & - & Safronova et al. (2006) \\
\hline & marginalis Dp1, & $\uparrow$ ACC-deaminase activity protecting pea & & \\
\hline & Rhodococcus sp. Fp2 & plants from growth inhibition & & \\
\hline & & $\uparrow$ Mineral uptake (N, K, Ca, Fe) & & \\
\hline \multirow[t]{7}{*}{ Vigna mungo } & Pseudomonas aeruginosa strains & $\uparrow$ Height, fresh and dry weight of roots and & PS & Ganesan (2008) \\
\hline & (MKRh1, MKRh3 and MKRh4) & shoots & & \\
\hline & (rhizosphere/native) & $\uparrow$ Extensive rooting & & \\
\hline & & $\downarrow$ Cd accumulation & & \\
\hline & & $\uparrow$ ACC-deaminase activity, IAA production, & & \\
\hline & & siderophore secretion and phosphate & & \\
\hline & & solubilization & & \\
\hline \multirow[t]{3}{*}{ Lupinus luteus } & Heavy metal resistant PGPRs & $\uparrow$ Biomass production and N content & PS & Dary et al. $(2010)^{*}$ \\
\hline & (rhizosphere/native) & $\downarrow$ Metals accumulation, especially in roots & & \\
\hline & & $\downarrow$ Metals translocated to the shoots & & \\
\hline \multirow[t]{3}{*}{ Glycine max } & Acidophilic P. putida 62BN and & $\downarrow C d$ concentration in plant and soil in their & PS & Rani et al. (2009) \\
\hline & alkalophilic Pseudomonas monteilli & respective soil types & & \\
\hline & 97AN strains & & & \\
\hline \multirow[t]{7}{*}{ Glycine max } & Cd-tolerant bacteria isolates from & $\uparrow$ Plant growth via IAA and siderophore & PS & Guo and Chi (2014) \\
\hline & nodules of Glycine max grown in heavy & production & & \\
\hline & metal-contaminated soil & $\uparrow$ ACC-deaminase activity and solubilisation & & \\
\hline & (rhizosphere/native) & of inorganic phosphate & & \\
\hline & & $\downarrow$ Cd accumulation by increasing Fe (and & & \\
\hline & & other mineral nutrients) availability & & \\
\hline & & (compared to Lolium multiflorum) & & \\
\hline
\end{tabular}

- Not mentioned. $\uparrow$ Increase; $\downarrow$ Decrease; PS, phytostabilization; PX, Phytoextraction. ${ }^{*}$ Cd and other metal(s). 
stimulation due to IAA production. The importance of IAA production in nodule formation enhancement by Pseudomonas strains has also been evidenced in the symbiosis of Rhizobium galegae-Galega orientalis (Egamberdieva et al., 2010), Bradyrhizobium-mung bean (Malik and Sindhu, 2011) and Sinorhizobium medicae-M. truncatula (Fox et al., 2011). After in vitro, glasshouse, and field experiments, Verma et al. (2012) observed that the dual inoculation of the helper PGPR Pseudomonas aeruginosa with Mesorhizobium sp. favored the acquisition of $\mathrm{P}$ and Fe in chickpea (Cicer arietinum) as a consequence of higher production of organic acids and siderophores, respectively. Furthermore, $P$. aeruginosa also increased significantly IAA production in chickpea, which ultimately stimulated root growth and the performance of nodulation and $\mathrm{N}_{2}$-fixation compared to inoculation with Mesorhizobium sp. alone.

However, little field research has been done to confirm the satisfactory results obtained under controlled experimental conditions (Table 2) surely due to the survival disadvantage of inoculated PGPRs in field trials as compared to well-adapted native strains (Rajkumar et al., 2012). Recent advances in molecular biology are contributing to overcome these experimental inconsistencies. Considerable attention has been directed toward genetic engineering of PGPRs and rhizobia to construct significantly improved strains, which express genes that confer adaptive characteristics to site-specific conditions as well as traits associated with plant growth promotion and metal tolerance (Zhuang etal., 2007). Indeed, recombinant PGPRs and rhizobia are advantageous for the expression of foreing genes coming from higher organisms like those encoding metallothioneins including phytochelatins. For instance, a recombinant Mesorrizobium huakuii carrying a tetrameric metallothionein (MTL4) and a phytochelatin synthase from Arabidopsis thaliana (AtPCS) favored Cd immobilization in nodules instead of stimulating its translocation in Astragalus sinicus (Ike et al., 2007). This is likely to ensure the establishment and survival of introduced PGPRs inoculants at the same time that increase the efficiency of phytoremediation. Nevertheless, regulatory issues and public acceptance of genetically engineered organisms may delay their commercialization and application (Kumar, 2012).

Overall, together with the inherent bacterial characteristic to biosorb metals, PGPRs are benefitial for the symbiotic interaction thanks to the regulation of plant hormone balance, notably by IAA production and through ethylene level control. In addition, $\mathrm{Lb}$ control of nodule low $\mathrm{O}_{2}$ levels is essential to protect Nase upon Cd exposure and PGPRs have been shown to somehow increase Lb content which could be a key aspect to sustain SNF under Cd stress. Besides, PGPRs-legume interaction also supports the establishment of seedlings and improves the vitality of legumes during metal phytoestabilization and phytoextraction strategies (Shilev et al., 2012). In Table 2 we have summarized some of the recent studies conducted with the aim of advancing in PGPRslegumes interaction in the interest of Cd-phytoremediation.

\section{CONCLUSION AND PERSPECTIVES}

Extensive research on the valuable cooperation of PGPRs and $\mathrm{N}_{2}$-fixing legumes for phytoremediation purposes has been performed and it is ongoing due to its enormous potential to renew
Cd-contaminated soils. However, there are several knowledge barriers which need to be addressed. Prominent among them are optimization of SNF under stressful conditions and a greater understanding of the ecology and dynamics of PGPRs under field conditions. In this respect, before inoculating soils with PGPRs, it must be considered that some strains might be pathogenic to some plant species and even allergenic for humans. Moreover, if the strains inoculated have been genetically modified the potential of horizontal gene transfer should be born in mind. It is also especially important the use and safe disposal of legume edible parts after phytoremediation process (i.e., roots, shoots, and seeds), since they could constitute an important route of $\mathrm{Cd}$ introduction in the food chain. For this reason, legumes used as phytoremediation tools should not be considered as products for animal feed or human consumption.

Finally, to boost the use of PGPRs-rhizobia-legume partnership the use of metagenomic approaches are essential to identify new bacterial strains with PGPR traits. Moreover, research should be focused in understanding the molecular mechanisms underlying the benefits of PGPRs on nitrogen fixation. In this sense, genetic engineering, a powerful tool that has still been poorly exploited in this area, should lead to the generation of strains better adapted to field conditions and with enhanced abilities to help legume-rhizobia symbiosis for effective Cd phytoremediation.

\section{ACKNOWLEDGMENTS}

The authors thank José María Becerril and Carlos Garbisu for helpful comments. The research leading to these results has received funding from the Basque Government (IT526-10; IT62413). MTGS is the recipient of a fellowship for recent doctors until their integration in postdoctoral programs by the Investigation Vice-rector's office of the University of the Basque Country UPV/EHU. We apologize to all colleagues whose work could not be discussed because of space limitations.

\section{REFERENCES}

Agency for Toxic Substances and Disease Registry (ATSDR). (2013). Toxicological Profile for Cadmium. Atlanta: U.S. Department of Health and Human Services, Public Health Service.

Ahemad, M., and Kibret, M. (2014). Mechanisms and applications of plant growth promoting rhizobacteria: current perspective. J. King. Saud. Univ. Sci. 26, 1-20. doi: 10.1016/j.jksus.2013.05.001

Ahmad, E., Zaidi, A., Khan, M. S., and Oves, M. (2012a). "Heavy metal toxicity to symbiotic nitrogen-fixing microorganism and host legumes," in Toxicity of Heavy Metals to Legumes and Bioremediation, eds A. Zaidi, P. A. Wani, and M. S. Khan (Vienna: Springer), 29-44. doi: 10.1007/978-3-7091-0730-0_2

Ahmad, M., Zahir, Z. A., Asghar, H. N., and Arshad, M. (2012b). The combined application of rhizobial strains and plant growth promoting rhizobacteria improves growth and productivity of mung bean (Vigna radiata L.) under salt-stressed conditions. Ann. Microbiol. 62, 1321-1330. doi: 10.1007/s13213011-0380-9

Balestrasse, K. B., Gallego, S. M., and Tomaro, M. L. (2004). Cadmium-induced senescence in nodules of soybean (Glycine max L.) plants. Plant Soil 262, 373381. doi: 10.1023/B:PLSO.0000037056.11877.7b

Balestrasse, K. B., Gallego, S. M., and Tomaro, M. L. (2006). Oxidation of the enzymes involved in nitrogen assimilation plays an important role in the cadmium-induced toxicity in soybean plants. Plant Soil 284, 187-194. doi: 10.1007/s11104-006-0050-z

Bianucci, E., Furlan, A., Rivadeneira, J., Sobrino-Plata, J., Carpena-Ruiz, R. O., and Tordable, M. D. C. (2013). Influence of cadmium on the symbiotic interaction established between peanut (Arachis hypogaea L.) and sensitive 
or tolerant bradyrhizobial strains. J. Environ. Manage. 130, 126-134. doi: 10.1016/j.jenvman.2013.08.056

Broos, K., Beyens, H., and Smolders, E. (2005). Survival of rhizobia in soil is sensitive to elevated zinc in the absence of the host plant. Soil Biol. Biochem. 37, 573-579. doi: 10.1016/j.soilbio.2004.08.018

Burger, J. (2008). Assessment and management of risk to wildlife from cadmium. Sci. Total Environ. 389, 37-45. doi: 10.1016/j.scitotenv.2007.08.037

Carpena, R. O., Vázquez, S., Esteban, E., Fernández-Pascual, M., de Felipe M. R., and Zornoza, P. (2003). Cadmium-stress in white lupin: effects on nodule structure and functioning. Plant Physiol. Biochem. 41, 911-919. doi: 10.1016/S0981-9428(03)00136-0

Cassán, F., Perrig, D., Sgroy, V., Masciarelli, O., Penna, C., and Luna, V. (2009). Azospirillum brasilense Az39 and Bradyrhizobium japonicum E109, inoculated singly or in combination, promote seed germination and early seedling growth in corn (Zea mays L.) and soybean (Glycine max L.). Eur. J. Soil Biol. 45, 28-35. doi: 10.1016/j.ejsobi.2008.08.005

Central Pollution Control Board [CPCB]. (2007). Cadmium Levels in Environment. News Letter Central Pollution Control Board New Delhi. Available at: http://wwcpcbnic.in/oldwebsite/news\%20letters/latest/cadmium/ch8cadmiumhtm [Accessed November 22, 2007].

Chaudri, A., McGrath, S., Gibbs, P., Chambers, B., Carlton-Smith, C., Bacon, J., et al. (2008). Population size of indigenous Rhizobium leguminosarum biovar trifoli in long-term field experiments with sewage sludge cake, metal-amended liquid sludge or metal salts: effects of zinc, copper and cadmium. Soil Biol. Biochem. 40, 1670-1680. doi: 10.1016/j.soilbio.2008.01.026

Chaudri, A. M., McGrath, S. P., and Giller, K. E. (1992). Survival of the indigenous population of Rhizobium leguminosarum biovar trifolii in soil spiked with Cd, Zn, Cu and Ni salts. Soil Biol. Biochem. 24, 625-632. doi: 10.1016/00380717(92)90040-5

Chen, Y. X., He, Y. F., Yang, Y., Yu, Y. L., Zheng, S. J., Tian, G. M., et al. (2003). Effect of cadmium on nodulation and $\mathrm{N}_{2}$-fixation of soybean in contaminated soils. Chemosphere 50, 781-787. doi: 10.1016/S0045-6535(02)00219-9

Clemens, S., Aarts, M. G., Thomine, S., and Verbruggen, N. (2013). Plant science: the key to preventing slow cadmium poisoning. Trends Plant Sci. 18, 92-99. doi: 10.1016/j.tplants.2012.08.003

Cuypers, A., Plusquin, M., Remans, T., Jozefczak, M., Keunen, E., Gielen, H., et al. (2010). Cadmium stress: an oxidative challenge. Biometals 23, 927-940. doi: 10.1007/s10534-010-9329-x

Dardanelli, M. S., Fernández de Córdoba, F. J., Espuny, M. R., Rodríguez Carvajal, M. A., Soria Díaz, M. E., Gil Serrano, A. M., et al. (2008). Effect of Azospirillum brasilense coinoculated with Rhizobium on Phaseolus vulgaris flavonoids and Nod factor production under salt stress. Soil Biol. Biochem. 40, 2713-2721. doi: 10.1016/j.soilbio.2008.06.016

Dary, M., Chamber-Pérez, M. A., Palomares, A. J., and Pajuelo, E. (2010). In situ phytostabilisation of heavy metal polluted soils using Lupinus luteus inoculated with metal resistant plant-growth promoting rhizobacteria. J. Hazard. Mater. 177, 323-330. doi: 10.1016/j.jhazmat.2009.12.035

Egamberdieva, D., Berg, G., Lindström, K., and Räsänen, L. A. (2010). Coinoculation of Pseudomonas spp. with Rhizobium improves growth and symbiotic performance of fodder galega (Galega orientalis Lam.). Eur. J. Soil Biol. 46, 269-272. doi: 10.1016/j.ejsobi.2010.01.005

Elkoca, E., Turan, M., and Donmez, M. F. (2010). Effects of single, dual and triple inoculations with Bacillus subtilis, Bacillus megaterium and Rhizobium leguminosarumbv. phaseoli on nodulation, nutrient uptake, yield and yield parameters of common bean (Phaseolus vulgaris l. cv.'elkoca-05'). J. Plant Nutr. 33, 2104-2119. doi: 10.1080/01904167.2010.519084

Engqvist, L. G., Mårtensson, A., Orlowska, E., Turnau, K., Belimov, A. A., Borisov, A. Y., et al. (2006). For a successful pea production on polluted soils, inoculation with beneficial microbes requires active interaction between the microbial components and the plant. Acta Agr. Scand. 56, 9-16.

Figueiredo, M. V., Burity, H. A., Martínez, C. R., and Chanway, C. P. (2008). Alleviation of drought stress in the common bean (Phaseolus vulgaris L.) by coinoculation with Paenibacillus polymyxa and Rhizobium tropici. Appl. Soil Ecol. 40, 182-188. doi: 10.1016/j.apsoil.2008.04.005

Fox, S. L., O'Hara, G. W., and Bräu, L. (2011). Enhanced nodulation and symbiotic effectiveness of Medicago truncatula when co-inoculated with Pseudomonas fluorescens WSM3457 and Ensifer (Sinorhizobium) medicae WSM419. Plant Soil 348, 245-254. doi: 10.1007/s11104-011-0959-8
Gallego, S. M., Pena, L. B., Barcia, R. A., Azpilicueta, C. E., Iannone, M. F., Rosales, E. P., etal. (2012). Unravelling cadmium toxicity and tolerance in plants: insight into regulatory mechanisms. Environ. Exp. Bot. 83, 33-46. doi: 10.1016/j.envexpbot.2012.04.006

Ganesan, V. (2008). Rhizoremediation of cadmium soil using a cadmium-resistant plant growth-promoting rhizopseudomonad. Curr. Microbiol. 56, 403-407. doi: 10.1007/s00284-008-9099-7

Garg, N., and Aggarwal, N. (2011). Effects of interactions between cadmium and lead on growth, nitrogen fixation, phytochelatin, and glutathione production in mycorrhizal Cajanus cajan (L.) Millsp. J. Plant Growth Regul. 30, 286-300. doi: 10.1007/s00344-010-9191-7

Garg, N., and Bhandari, P. (2012). Influence of cadmium stress and arbuscular mycorrhizal fungi on nodule senescence in Cajanus cajan (L.) Millsp. Int. J. Phytoremediation 14, 62-74. doi: 10.1080/15226514.2011.573822

Gerhardt, K. E., Huang, X.-D., Glick, B. R., and Greenberg, B. M. (2009). Phytoremediation and rhizoremediation of organic soil contaminants: potential and challenges. Plant Sci. J. 176, 20-30. doi: 10.1016/j.plantsci.2008.09.014

Giller, K. E., Witter, E., and Mcgrath, S. P. (1998). Toxicity of heavy metals to microorganisms and microbial processes in agricultural soils: a review. Soil Biol. Biochem. 30, 1389-1414. doi: 10.1016/S0038-0717(97)00270-8

Guo, J., and Chi, J. (2014). Effect of Cd-tolerant plant growth-promoting Rhizobium on plant growth and Cd uptake by Lolium multiflorum Lam. and Glycine max (L.) Merr. in Cd-contaminated soil. Plant Soil 375, 205-214. doi: 10.1007/s11104-0131952-1

Hayat, R., Ali, S., Amara, U., Khalid, R., and Ahmed, I. (2010). Soil beneficial bacteria and their role in plant growth promotion: a review. Ann. Microbiol. 60, 579-598. doi: 10.1007/s13213-010-0117-1

Hernández, L. E., Garate, A., and Carpena-Ruiz, R. (1995). Effect of cadmium on nitrogen fixing pea plants grown in perlite and vermiculite 1. J. Plant Nutr. 18, 287-303. doi: 10.1080/01904169509364902

Ike, A., Sriprang, R., Ono, H., Murooka, Y., and Yamashita, M. (2007). Bioremediation of cadmium contaminated soil using symbiosis between leguminous plant and recombinant rhizobia with the MTL4 and the PCS genes. Chemosphere 66, 1670-1676. doi: 10.1016/j.chemosphere.2006.07.058

Iqbal, M. A., Khalid, M., Shahzad, S. M., Ahmad, M., Soleman, N., and Akhtar, N. (2012). Integrated use of Rhizobium leguminosarum, plant growth promoting rhizobacteria and enriched compost for improving growth, nodulation and yield of lentil (Lens culinaris Medik.). Chil. J. Agr. Res. 72, 104-110. doi: 10.4067/S071858392012000100017

Kumar, A. (2012). "Role of plant-growth-promoting rhizobacteria in the management of cadmium-contaminated soil," in Toxicity of Heavy Metals to Legumes and Bioremediation, eds A. Zaidi, P. A. Wani, and M. S. Khan (Vienna: Springer), 163-178. doi: 10.1007/978-3-7091-0730-0_10

Larrainzar, E., Gil-Quintana, E., Arrese-Igor, C., González, E. M., and Marino, D. (2014). Split-root systems applied to the study of the legume-rhizobial symbiosis: what have we learned? J. Integr. Plant Biol. 56, 1118-1124. doi: 10.1111/jipb.12231

Lewis, G. P., Schrire, B., Mackinder, B., and Lock, M. (2005). Legumes of the World. Richmond, VA: Kew Publishing.

Lichtfouse, E. (2009). Organic Farming, Pest Control and Remediation of Soil Pollutants. Dordrecht: Springer Science+Business Media B.V.

Loscos, J., Matamoros, M. A., and Becana, M. (2008). Ascorbate and homoglutathione metabolism in common bean nodules under stress conditions and during natural senescence. J. Plant Physiol. 146, 1282-1292. doi: 10.1104/pp.107.114066

Malik, D. K., and Sindhu, S. S. (2011). Production of indole acetic acid by Pseudomonas sp.: effect of coinoculation with Mesorhizobium sp. Cicer on nodulation and plant growth of chickpea (Cicer arietinum). Physiol. Mol. Biol. Plants 17, 25-32. doi: 10.1007/s12298-010-0041-7

Manier, N., Deram, A., Broos, K., Denayer, F. O., and Van Haluwyn, C. (2009). White clover nodulation index in heavy metal contaminated soils-a potential bioindicator. J. Environ. Qual. 38, 685-692. doi: 10.2134/jeq2008.0013

Marino, D., Damiani, I., Gucciardo, S., Mijangos, I., Pauly, N., and Puppo, A. (2013). Inhibition of nitrogen fixation in symbiotic Medicago truncatula upon Cd exposure is a local process involving leghemoglobin. J. Exp. Bot. 64, 5651-5660. doi: $10.1093 /$ jxb/ert334

Marino, D., González, E. M., and Arrese-Igor, C. (2006). Drought effects on carbon and nitrogen metabolism of pea nodules can be mimicked by paraquat: evidence for the occurrence of two regulation pathways under oxidative stresses. J. Exp. Bot. 57, 665-673. doi: 10.1093/jxb/erj056 
Marino, D., Pucciariello, C., Puppo, A., and Frendo, P. (2009). The redox state, a referee of the legume-rhizobia symbiotic game. Adv. Bot. Res. 52, 115-151. doi: 10.1016/S0065-2296(10)52005-6

Mathieu, C., Moreau, S., Frendo, P., Puppo, A., and Davies, M. J. (1998). Direct detection of radicals in intact soybean nodules: presence of nitric oxide-leghemoglobin complexes. Free Radic. Biol. Med. 24, 1242-1249. doi 10.1016/S0891-5849(97)00440-1

Mehboob, I., Naveed, M., Zahir, Z. A., and Sessitsch, A. (2013). "Potential of rhizosphere bacteria for improving Rhizobium-legume symbiosis," in Plant Microbe Symbiosis: Fundamentals and Advances, ed. N. K. Arora (New Delhi: Springer), 305-349. doi: 10.1007/978-81-322-1287-4_12

Mishra, P. K., Bisht, S. C., Ruwari, P., Joshi, G. K., Singh, G., Bisht, J. K., et al. (2011). Bioassociative effect of cold tolerant Pseudomonas spp. and Rhizobium leguminosarum-PR1 on iron acquisition, nutrient uptake and growth of lentil (Lens culinaris L.). Eur. J. Soil Biol. 47, 35-43. doi: 10.1016/j.ejsobi.2010. 11.005

Mishra, P. K., Mishra, S., Selvakumar, G., Bisht, J. K., Kundu, S., and Gupta, H. S. (2009a). Coinoculation of Bacillus thuringeinsis-KR1 with Rhizobium leguminosarum enhances plant growth and nodulation of pea (Pisum sativum L.) and lentil (Lens culinaris L.). World J. Microb. Biot. 25, 753-761. doi: 10.1007/s11274-009-9963-z

Mishra, P. K., Mishra, S., Selvakumar, G., Kundu, S., and Shankar Gupta, H. (2009b). Enhanced soybean (Glycine max L.) plant growth and nodulation by Bradyrhizobium japonicum-SB1 in presence of Bacillus thuringiensis-KR1. Acta Agric. Scand. B Soil Plant. Sci. 59, 189-196. doi: 10.1080/09064710802040558

Muneer, S., Kim, T. H., and Qureshi, M. I. (2012). Fe modulates Cd-induced oxidative stress and the expression of stress responsive proteins in the nodules of Vigna radiata. Plant Growth Regul. 68, 421-433. doi: 10.1007/s10725-0129731-1

Naya, L., Ladrera, R., Ramos, J., González, E. M., Arrese-Igor, C., Minchin, F. R., et al. (2007). The response of carbon metabolism and antioxidant defenses of alfalfa nodules to drought stress and to the subsequent recovery of plants. J. Plant Physiol. 144, 1104-1114. doi: 10.1104/pp.107.099648

Neumann, H., Bode-Kirchhoff, A., Madeheim, A., and Wetzel, A. (1998). Toxicity testing of heavy metals with the Rhizobium-legume symbiosis: high sensitivity to cadmium and arsenic compounds. Environ. Sci. Pollut. Res. Int. 5, 28-36. doi: 10.1007/BF02986371

Oldroyd, G. E. D. (2013). Speak, fried, and enter: signalling systems that promote beneficial symbiotic associations in plants. Nat. Rev. Microbiol. 11, 252-263. doi: 10.1038/nrmicro2990

Pajuelo, E., Carrasco, J. A., Romero, L. C., Chamber, M. A., and Gotor, C. (2007). Evaluation of the metal phytoextraction potential of crop legumes. Regulation of the expression of O-acetylserine (thiol) lyase under metal stress. Plant Biol. 9, 672-681. doi: 10.1055/s-2007-965439

Rajendran, G., Sing, F., Desai, A. J., and Archana, G. (2008). Enhanced growth and nodulation of pigeon pea by co-inoculation of Bacillus strains with Rhizobium spp. Bioresour. Technol. 99, 4544-4550. doi: 10.1016/j.biortech.2007.06.057

Rajkumar, M., Sandhya, S., Prasad, M. N. V., and Freitas, H. (2012). Perspectives of plant-associated microbes in heavy metal phytoremediation. Biotechnol. Adv. 30, 1562-1574. doi: 10.1016/j.biotechadv.2012.04.011

Rani, A., Souche, Y. S., and Goel, R. (2009). Comparative assessment of in situ bioremediation potential of cadmium resistant acidophilic Pseudomonas putida 62BN and alkalophilic Pseudomonas monteilli 97AN strains on soybean. Int. Biodeterior. Biodegradation 63, 62-66. doi: 10.1016/j.ibiod.2008. 07.002

Redondo, F. J., de la Peña, T. C., Morcillo, C. N., Lucas, M. M., and Pueyo, J. J. (2009). Overexpression of flavodoxin in bacteroids induces changes in antioxidant metabolism leading to delayed senescence and starch accumulation in alfalfa root nodules. J. Plant Physiol. 149, 1166-1178. doi: 10.1104/pp.108. 129601

Remans, R., Beebe, S., Blair, M., Manrique, G., Tovar, E., Rao, I., et al. (2008). Physiological and genetic analysis of root responsiveness to auxin-producing plant growth-promoting bacteria in common bean (Phaseolus vulgaris L.). Plant Soil 302, 149-161. doi: 10.1007/s11104-007-9462-7

Romero-Puertas, M. C., Rodríguez-Serrano, M., Corpas, F. J., Gomez, M. D., Del Rio, L. A., and Sandalio, L. M. (2004). Cadmium-induced subcellular accumulation of $\mathrm{O}_{2}$ - and $\mathrm{H}_{2} \mathrm{O}_{2}$ in pea leaves. Plant Cell Environ. 27, 1122-1134. doi: 10.1111/j.1365-3040.2004.01217.x
Safronova, V. I., Stepanok, V. V., Engqvist, G. L., Alekseyev, Y. V., and Belimov, A. A. (2006). Root-associated bacteria containing 1-aminocyclopropane-1-carboxylate deaminase improve growth and nutrient uptake by pea genotypes cultivated in cadmium supplemented soil. Biol. Fertil. Soils 42, 267-272. doi: 10.1007/s00374005-0024-y

Salin, M. L. (1988). Toxic oxygen species and protective systems of the chloroplast. Physiol. Plant 72, 681-689. doi: 10.1111/j.1399-3054.1988.tb 09182.x

Salt, D. E., Blaylock, M., Kumar, N. P., Dushenkov, V., Ensley, B. D., Chet, I., et al. (1995). Phytoremediation: a novel strategy for the removal of toxic metals from the environment using plants. Nat. Biotechnol. 13, 468-474. doi: 10.1038/nbt0595-468

Sánchez-Pardo, B., Carpena, R. O., and Zornoza, P. (2013). Cadmium in white lupin nodules: impact on nitrogen and carbon metabolism. J. Plant Physiol. 170, 265-271. doi: 10.1016/j.jplph.2012.10.001

Sandalio, L. M., Dalurzo, H. C., Gomez, M., Romero-Puertas, M. C., and Del Rio, L. A. (2001). Cadmium-induced changes in the growth and oxidative metabolism of pea plants. J. Exp. Bot. 52, 2115-2126. doi: 10.1093/jexbot/52. 364.2115

Sessitsch, A., Kuffner, M., Kidd, P., Vangronsveld, J., Wenzel, W. W., Fallmann, K., et al. (2013). The role of plant-associated bacteria in the mobilization and phytoextraction of trace elements in contaminated soils. Soil Biol. Biochem. 60, 182-194. doi: 10.1016/j.soilbio.2013.01.012

Shaharoona, B., Arshad, M., and Zahir, Z. A. (2006). Effect of plant growth promoting rhizobacteria containing ACC-deaminase on maize (Zea mays L.) growth under axenic conditions and on nodulation in mung bean (Vigna radiata L.). Lett. Appl. Microbiol. 42, 155-159. doi: 10.1111/j.1472-765X.2005. 01827.x

Sheirdil, R. A., Bashir, K., Hayat, R., and Akhtar, M. S. (2012). Effect of cadmium on soybean (Glycine max L.) growth and nitrogen fixation. Afr. J. Biotechnol. 11, 1886-1891.

Shilev, S., Naydenov, M., Prieto, M. S., Vassilev, N., and Sancho, E. D. (2012). "PGPR as inoculants in management of lands contaminated with trace elements," in Bacteria in Agrobiology: Stress Management, ed. D. K. Maheshwari (Berlin: Springer), 259-277.

Shvaleva, A., de la Peña, T. C., Rincón, A., Morcillo, C. N., de la Torre, V. S. G., Lucas, M. M., et al. (2010). Flavodoxin overexpression reduces cadmium-induced damage in alfalfa root nodules. Plant Soil 326, 109-121. doi: 10.1007/s11104-0099985-1

Smith, S. R. (1997). Rhizobium in soils contaminated with copper and zinc following the long-term application of sewage sludge and other organic wastes. Soil Biol. Biochem. 29, 1475-1489. doi: 10.1016/S0038-0717(97) 00036-9

Tripathi, M., Munot, H. P., Shouche, Y., Meyer, J. M., and Goel, R. (2005). Isolation and functional characterization of siderophore-producing lead-and cadmium-resistant Pseudomonas putida KNP9. Curr. Microbiol. 50, 233-237. doi: 10.1007/s00284-004-4459-4

United States Department of Agriculture, Economic Research Service [USDA-ERS]. (2013). U.S. Fertilizer Imports/Exports. USDA. Available at: http://www.ers.usda.gov/data-products/fertilizer-use-and-price.aspx\#26727 [accessed July 12, 2013].

Velázquez, E., García-Fraile, P., Ramírez-Bahena, M. H., Rivas, R., and MartínezMolina, E. (2010). "Bacteria involved in nitrogen-fixing legume symbiosis: current taxonomic perspective," in Microbes for Legume Improvement, eds M. S. Khan, A. Zaidi, and J. Musarrat (Vienna: Springer), 1-25.

Verma, J. P., Yadav, J., and Tiwari, K. N. (2012). Enhancement of nodulation and yield of chickpea by co-inoculation of indigenous Mesorhizobium spp. and plant growth-promoting rhizobacteria in Eastern Uttar Pradesh. Commun. Soil Sci. Plant Anal. 43, 605-621. doi: 10.1080/00103624.2012. 639110

Wong, M. H. (2003). Ecological restoration of mine degraded soils, with emphasis on metal contaminated soils. Chemosphere 50, 775-780. doi: 10.1016/S00456535(02)00232-1

Zahir, Z. A., Zafar-ul-Hye, M., Sajjad, S., and Naveed, M. (2011). Comparative effectiveness of Pseudomonas and Serratia sp. containing ACC-deaminase for coinoculation with Rhizobium leguminosarum to improve growth, nodulation, and yield of lentil. Biol. Fertil. Soils. 47, 457-465. doi: 10.1007/s00374-0110551-7 
Zaidi, A., Wani, P. A., and Khan, M. S. (2012). Toxicity of Heavy Metals to Legumes and Bioremediation. Dordrecht: Springer. doi: 10.1007/978-3-7091-0730-0

Zhuang, X., Chen, J., Shim, H., and Bai, Z. (2007). New advances in plant growthpromoting rhizobacteria for bioremediation. Environ. Int. 33, 406-413. doi: 10.1016/j.envint.2006.12.005

Conflict of Interest Statement: The authors declare that the research was conducted in the absence of any commercial or financial relationships that could be construed as a potential conflict of interest.

Received: 28 August 2014; accepted: 30 January 2015; published online: 25 February 2015 .
Citation: Gómez-Sagasti MT and Marino D (2015) PGPRs and nitrogen-fixing legumes: a perfect team for efficient Cd phytoremediation? Front. Plant Sci. 6:81. doi: $10.3389 /$ fpls.2015.00081

This article was submitted to Plant Biotechnology, a section of the journal Frontiers in Plant Science.

Copyright (c) 2015 Gómez-Sagasti and Marino. This is an open-access article distributed under the terms of the Creative Commons Attribution License (CC BY).

The use, distribution or reproduction in other forums is permitted, provided the original author(s) or licensor are credited and that the original publication in this journal is cited, in accordance with accepted academic practice. No use, distribution or reproduction is permitted which does not comply with these terms. 